\title{
A ESCRITA DA HISTÓRIA E OS CONTEÚDOS ENSINADOS NA DISCIPLINA DE HISTÓRIA NO ENSINO FUNDAMENTAL ${ }^{1}$
}

\author{
Marlene Cainelli*
}

\begin{abstract}
RESUMO
Trabalhar questões relativas ao ensino de História e a História da Educação na educação básica está relacionado historicamente à seleção de conteúdos para ensinar História. Entre os principais fundamentos deste olhar historiográfico para o ensino de História está a importância do pensamento histórico para este processo. Autores como Rusen (1998, 2001) Lee $(2001,2006)$ e Schmidt (2009) argumentam que para se investigar a aprendizagem histórica é preciso ter como referência teórica e metodológica a ciência da História. Nesta pesquisa que realizamos pretendemos discutir como os conteúdos da História ensinada são determinados e postos em prática em sala de aula. A seleção e definição de conteúdos escolares pressupõem uma determinada concepção de história além das demandas relacionadas aos poderes constituídos, nesse sentido definir o que se ensina na disciplina de História caracteriza-se por disputas em torno da memória, constituição da nação e de seus sujeitos.
\end{abstract}

Palavras-chave: Educação histórica. Ensino de História. Historiografia. História da educação.

\begin{abstract}
To work with questions related to the teaching of history and the history of education in elementary and middle schools involves the study on how history contents have been selected, historically. Among the main fundamentals behind this historiographic look into the teaching of history is the importance of the historical thought for this process. Authors such as Rusen (1998, 2001), Lee $(2001,2006)$ and Schmidt (2009) argue on the
\end{abstract}

\footnotetext{
* Doutorado em História pela Universidade Federal do Paraná (UFPR). Professora de Metodologia do Ensino de História e do Programa de Mestrado em Educação da Universidade Estadual de Londrina (UEL).E-mail: cainelli@uel.br

1 Este artigo é originário de discussão e leituras no âmbito do projeto de pesquisa Educação Histórica: um estudo sobre a aprendizagem da história no processo de transição para a quinta série ( $\left.6^{\circ} \mathrm{ano}\right)$ do ensino fundamental, financiado pelo edital de Ciências Humanas do CNPQ e pelo edital de pesquisa aplicada da Fundação Araucária.
} 
impossibility to understand history learning without having the science of History as the theoretical and methodological reference. School content selection presupposes, from the teachers, didactic and curricular manuals standpoint, a determined historical concept. School History contents also involve demands related to constituted powers, and, in this sense, to define what to teach in the subject of History is characterized by disputes on memory, nation constitution and their subjects.

Keywords: Historical education. History's teaching. Historiography. History of education.

\section{Introdução}

Sabe-se que os alunos têm idéias sobre o passado e sobre a história indiferente do que e como nós o ensinamos. O passado é inescapável; ele é construído em nossas formas de pensar sobre nós mesmos (LEE, 2001).

Uma das discussões mais importantes hoje quando trabalhamos questões relativas ao ensino de História diz respeito à aprendizagem da história e a seleção de conteúdos para ensinar. Como crianças e adolescentes aprendem história? Quais as operações cognitivas necessárias para esta aprendizagem?

Estas questões trazem para o campo da aprendizagem e do ensino de História discussões que envolvem basicamente a retomada por parte da ciência da história ${ }^{2}$ do método e da forma de ensinar, aquilo que denominamos de didática da história. Entre os principais fundamentos

\footnotetext{
2 Chamamos de retomada para a ciência da história principalmente questões relacionadas ao método e aos conteúdos a serem ensinados no ensino fundamental e médio. Visto que até o final do século XX a seleção de conteúdos, principalmente a questão dos círculos concêntricos e a aprendizagem da história nas séries iniciais, eram pensados pelas lentes da psicologia (teoria piagetiana) e da pedagogia no que se refere a forma de ensinar. $\mathrm{O}$ historiador Jorh Rusen (2001) também argumenta que este afastamento da ciência da história das formas de ensino da sua matéria deu-se a partir do século XIX com a profissionalização dos historiadores, e com a criação da disciplina os historiadores começam a perder de vista um importante princípio: que a história é enraizada nas necessidades sociais para orientar a vida dentro da estrutura tempo. Como os historiadores do século XIX se esforçaram para tornar a história uma ciência, este público foi esquecido ou redefinido para incluir apenas um pequeno grupo de profissionais especialistas treinados (RUSEN, 2007, p. 5).
} 
deste olhar para o ensino de História a partir de sua ciência de referência está o pensar a aprendizagem da história tendo como ponto de partida o desenvolvimento do pensamento histórico.

Autores como Rusen (1998, 2001) Lee (2001, 2006) e Schmidt (2009) argumentam a impossibilidade de se entender a aprendizagem histórica sem ter como referência teórica e metodológica a ciência da História. Schmidt (2009) utiliza a expressão cognição histórica situada para caracterizar a ideia de que aprender história demandaria uma operação cognitiva relacionada à racionalidade histórica e a percepção por parte dos sujeitos de uma consciência histórica. Schmidt argumenta:

Aprender é um processo dinâmico, no qual a pessoa que aprende muda porque algo é obtido, algo é adquirido, num insight, habilidade, ou mistura de ambos. No aprendizado histórico a "história" é obtida porque fatos objetivos, coisas, que aconteceram no tempo tornamse uma questão de conhecimento consciente, ou seja, eles tornam-se subjetivos (SCHMIDT, 2009 p. 33).

Nesta forma de entender a aprendizagem da história, o significado dos conteúdos a serem ensinados altera-se em seu sentido e forma. A seleção de conteúdos escolares pressupõe por parte de professores, manuais curriculares e manuais didáticos uma determinada concepção de história. As definições de conteúdos históricos escolares envolvem também as demandas relacionadas aos poderes constituídos, nesse sentido definir o que se ensina na disciplina de história caracteriza-se antes de tudo por disputas em torno da memória e constituição da nação e de seus sujeitos.

$\mathrm{O}$ fato de termos que selecionar conteúdos e fazer escolhas sobre o que ensinar, nos remete a uma questão importante, tudo seria história? Como converter esta imensidão de possibilidades em escolhas? Segundo Eric Hobsbawm "todo estudo histórico, portanto, implica uma seleção minúscula, de algumas coisas da infinidade de atividades humanas do passado, e aquilo que afetou essas atividades. Mas não há nenhum critério geral aceito para se fazer tal seleção" (HOBSBAWM, 1998, p. 71). 


\section{História do ensino de História: historiografia, conteúdos e manuais didáticos}

Quando a disciplina de História é instituída no Brasil, em meados do século XIX, os conteúdos definidos como essenciais para serem ensinados remontaram a questões da história da civilização europeia, mais precisamente da civilização ocidental. Assim, como os conteúdos estavam relacionados à História da civilização, a forma de desenvolvimento destes conteúdos seguia a teoria Ranqueana ${ }^{3}$ de que cada fato histórico é único e sem possibilidade de repetição; a história deveria ser reconstituída de forma objetiva sem subjetividades para ser considerada como verdadeira e assim sendo científica. É também neste período de constituição dos estados nacionais que a história ganha seus objetivos mais duradouros para servir de instrumento para consolidação dos estados nacionais, constituindo-se em espaços de propagação dos feitos de seus heróis por meio das atitudes dos estados representados por seus comandantes.

No caso brasileiro, estas características dos conteúdos escolares se tornam preponderantes após a proclamação da república com a introdução de História do Brasil nos currículos das escolas primárias e secundárias. Neste período, a definição dos conteúdos escolares coube a um grupo de professores do Colégio D. Pedro II, situado no Rio de Janeiro, e também a membros do Instituto Histórico Geográfico Brasileiro (IHGB), que a partir de estudos realizados definiram quais conteúdos sobre a história do Brasil seriam trabalhados na escola. Foram definidos conteúdos relacionados à história pátria e à constituição do povo brasileiro. Elza Nadai comenta que:

O século XIX acrescentou paralelamente aos grandes movimentos que ocorreram visando construir os estados nacionais sob hegemonia burguesa, a necessidade de retornar-se ao passado, com o objetivo de identificar a base comum formadora da nacionalidade. Daí os conceitos tão caros ás histórias nacionais, Pátria, Nacionalidade, Cidadania (NADAI, 1986, p. 106).

3 Leopold Von Ranque (1795-1886). 
É a partir do IHGB que se consolidaria a História nacional que teria como modelo alguns fatos que acabariam por transformar-se referência em torno dos quais todo um conjunto de acontecimentos tornar-se-iam indicativos de conteúdo. O descobrimento do Brasil, a independência, entre outros fatos são vistos dentro desta perspectiva como marcos fundadores da História do Brasil, contada a partir de 1500, quando os europeus aportaram em nosso território.

Estes conceitos e marcos temporais, definidos a partir da formação dos estados nacionais acompanharam o ensino de História por vários anos. O processo de consolidação da disciplina de História nos currículos das escolas brasileiras sempre envolveu uma grande discussão em torno da história pátria. Diante dos objetivos em torno de referendar a constituição de uma nação, a história do Brasil institucionalizou-se enquanto conteúdo escolar como uma história basicamente relacionada a questões políticas. Seguindo esta direção, os livros didáticos selecionaram os conteúdos tendo como referencial a história política do País e da Europa.

Durante o século $\mathrm{XX}$, os conteúdos relacionados à história política foram predominantes no ensino de história. Os manuais didáticos destinados a crianças e a adolescentes contemplavam como conteúdos a história das instituições políticas brasileira, a história dos governos, dos lideres governamentais, das disputas em torno do poder sejam por guerras, revoluções ou revoltas. As mudanças na forma de ensinar história não acompanharam nestes anos o mesmo ritmo das mudanças historiográficas ${ }^{4}$. Os conteúdos ensinados em História demoram mais para serem modificados, repensados. A estrutura escolar e os materiais destinados para o ensino de história permanecem por mais tempo inalterados.

Das mudanças historiográficas que produziram alguma interferência na seleção de conteúdos no ensino fundamental e médio, a história marxista ${ }^{5}$ foi a que causou maior impacto principalmente na forma

\footnotetext{
4 Neste século, varias mudanças historiográficas repensaram a escrita da história e seus métodos. Como a história marxista, história dos Annalles, Nova história cultural.

5 A análise marxista parte das estruturas presentes com a finalidade de orientar a práxis social, e tais estruturas conduzem à percepção de fatores formados no passado, cujo conhecimento é útil para a atuação da realidade hodierna (BITTENCOURT, C. M. F. Ensino de História: fundamentos e métodos. São Paulo: Cortez, 2004, p. 145).
} 
de abordagem dos velhos conteúdos políticos. A teoria marxista modificou a forma de composição dos conteúdos ao pressupor como objetivo para o ensino de História a constituição de cidadãos com capacidade de crítica do social. Este entendimento de um ensino de História centrado na formação de cidadãos não modificou sensivelmente os conteúdos ensinados que ainda recaíam sobre a história política a partir deste momento vista pela ótica das classes sociais.

No que se refere à produção didática, o paradigma marxista modificou a estrutura dos manuais ao organizar os conteúdos a partir das questões econômicas. Bittencourt afirma:

O denominado materialismo histórico serviu de base para a elaboração de muitas obras didáticas condição que consolidou a organização de conteúdos da história das sociedades do mundo ocidental pelos modos de produção e pela luta de classes. Os conteúdos escolares foram organizados pela formação econômica das sociedades, situando os indivíduos de acordo com o lugar ocupado por eles no processo produtivo. Burguesia, proletariado, aristocracia são os sujeitos sociais que fornecem visibilidade ás ações da sociedade, e os confrontos entre diversos grupos sociais explicam as mudanças e permanências históricas (BITTENCOURT, 2006, p. 146-147).

As mudanças neste período dizem respeito à forma de abordagem de conteúdos tradicionais no ensino de História, pois não há ainda o propósito de pensar os conteúdos escolares na perspectiva daquilo que significam para as crianças e adolescentes. A seleção dos conteúdos é pensada a partir daquilo que significam como domínio do saber disciplinar dos professores e não vinculam-se a um critério de seleção baseado, direta ou indiretamente, nos problemas do aluno e da sua vida em sua condição social cultural (BITTENCOURT, 2006, p. 137).

Os conteúdos tradicionais trabalhados no ensino fundamental começam a sofrer alterações significativas apenas em meados do século XX. A renovação temática e a inclusão de novos objetos proporcionaram mudanças significativas no entendimento do que vem a ser conteúdos em História. Temáticas como mulheres, crianças, religiosidades e porque não 
dizer temas relacionados à própria estrutura do conhecimento histórico como fontes, documentos e temporalidade começam a fazer parte dos conteúdos em História, sendo que de forma lenta as mudanças atingem também os manuais didáticos. No entanto, é preciso levar em consideração que apenas as mudanças na forma de produzir o conhecimento histórico, ou seja, as mudanças historiográficas não proporcionam modificações substanciais na forma de ensinar história. É necessário um movimento articulado entre as renovações da historiografia e as renovações na forma de ensinar História para que haja significativamente uma mudança na forma de seleção dos conteúdos.

Bourne ao falar do ensino de História na França traz um argumento que pode muito bem ser utilizado para o ensino de História no Brasil:

Todo ensino é uma busca de sentido, explícita ou implícita. Por muito tempo, o professor de história orientou seu ensino de acordo com uma ideologia do progresso, que reservava à França um papel particular em sua realização. Hoje, duvida-se do progresso, afirma-se menos frequentemente a excepcionalidade francesa. $\mathrm{O}$ ensino ainda pode, sem dúvida, afirmar finalidades cívicas e culturais, mas hesita em ser o vetor de certezas militantes. Essa mutação deve ser assumida como libertadora (BOURNE, 1998, p. 139).

Este movimento articulado entre as mudanças historiográficas e o novo pensar metodológico acontecem no ensino de História a partir de discussões que remetem a problemática do ensino reprodutivista nas escolas do ensino fundamental e médio. Isto ocorre no final da década de 1980 do século XX. Conjuntamente com as mudanças políticas no Brasil ${ }^{6}$, há um movimento de reformulação da forma de ensinar História no ensino fundamental. Começa-se a pensar o professor e o aluno como sujeitos do conhecimento e a escola como um espaço de produção de conhecimento e não apenas como um lugar de disseminação de conhecimentos produzidos.

6 Aqui estamos nos referindo ao Movimento de Redemocratização no Brasil pós-ditadura militar, na década de 1980 . 
Neste período ganha força as teorias em torno da transposição didática $^{7}$. O professor nesta proposição teria o papel de selecionar os conteúdos a serem ensinados escolarmente a partir de uma transposição do saber científico. Algumas críticas são feitas a esta teoria, a principal delas diz respeito ao entendimento de que esta transposição poderia significar uma simplificação dos conteúdos a serem ensinados, transformando a disciplina escolar em mero instrumento de disseminação dos saberes científicos.

Neste movimento de repensar a forma de ensinar História, a seleção de conteúdos também foi questionada. Afinal, quais seriam os conteúdos essenciais para o ensino de História. Bourne afirma que:

Ensinar a história é, em primeiro lugar, levar os alunos a se apropriarem de uma linguagem específica. Neste sentido, os conteúdos do ensino são inseparáveis das modalidades de sua transmissão. Apropriar-se de uma linguagem não passa por uma simples memorização, e sim pela aprendizagem das operações intelectuais que permitem a construção de um discurso. Como o historiador mas no nível que lhe é próprio, o aluno deve descobrir, analisar, classificar. Em suma, operar um ordenamento no tempo (BOURNE, 1998, p. 139).

Não podemos esquecer que neste período o ensino de História retorna ao ensino fundamental como disciplina autônoma depois de ter sido destituído no período da ditadura militar e conjuntamente com a Geografia tornar-se a disciplina de Estudos Sociais. ${ }^{8}$ Segundo Oliveira (2003), a

\footnotetext{
7 Transposição didática é um processo de transformação científica, didática até sua tradução no campo escolar. Ela permite pensar a transformação de um saber científico e social que afeta os objetos de conhecimento em um saber a ensinar, tal qual aparece nos programas, manuais, na palavra do professor, considerados não somente científicos. (...) Isso significa, então, um verdadeiro processo de criação e não somente de simplificação, redução (INRP, 1989, p. 14 apud SCHMIDT; CAINELLI, 1989, p. 31).

8 A disciplina de Estudos Sociais foi criada no período da ditadura militar eliminandose do currículo das escolas no ensino fundamental as disciplinas de História e Geografia. Também foram criadas neste período as disciplinas de Educação Moral e Cívica para o ensino fundamental e Organização Social e Política Brasileira para o ensino médio, que tinham como objetivo discutir questões ligadas ao civismo e a pátria brasileira.
} 
constituição de disciplinas autônomas nas séries iniciais posterior a ditadura militar não levou em consideração a especificidade da aprendizagem e da formação de professores para este nível de escolarização. Para a autora, muitas perguntas ficaram sem resposta, como: Como esta divisão foi e se foi incorporada pelo professor generalista (que trabalha com todas as áreas do conhecimento) no cotidiano escolar, a mudança de estudos sociais para história e geografia? Essa mudança ocorreu efetivamente na prática pedagógica? O professor generalista compreende as áreas em sua especificidade? (OLIVEIRA, 2003, p. 260). Nós acrescentaríamos a estas questões: Como o professor generalista seleciona e trabalha os conteúdos de história em sala de aula? e Como os livros didáticos se adaptaram a estas modificações?

Quando foram estabelecidos os novos parâmetros para educação básica no Brasil por meio da promulgação da Lei n. 9394/96, que estabelece as Diretrizes e Bases da Educação Nacional, ficou evidenciado uma nova forma de pensar a aprendizagem. Segundo Holien Bezerra:

os objetivos da educação básica não se restringem a assimilação maior ou menor de conteúdos prefixados, mas se comprometem a articular conhecimento, competências e valores, com a finalidade de capacitar os alunos a utilizarem-se das informações para a transformação de sua própria personalidade, assim como para atuar de maneira efetiva na transformação da sociedade (BEZERRA, 2003, p. 37).

Na primeira avaliação ${ }^{9}$ de livros didáticos realizada pelo Ministério da Educação, em que os livros de História e Geografia são avaliados de forma separada. Em 1998, este entendimento sobre a amplitude dos conteúdos aparecem nos seguintes objetivos para área de História:

Formação do cidadão, como indivíduo situado historicamente, consciente da sua dimensão social, no seu tempo, e capaz de entender

\footnotetext{
9 A avaliação de livros didáticos no Brasil faz parte do Programa Nacional de Livros Didáticos do Ministério da Educação. Este programa foi criado em 1985. O primeiro guia de livros didáticos para $1^{\mathrm{a}}$ a $4^{\mathrm{a}}$ séries do ensino fundamental foi publicado em 1997.
} 
e analisar a dinâmica das organizações sociais, cuja influencia exerce - em diferentes locais e momentos - sobre os mais variados aspectos da vida cotidiana, e também sobre os diferentes processos históricos. Esse objetivo se concretiza mediante a aquisição de um conjunto de conhecimentos, fundados em conceitos como os de tempo, espaço, cultura, sociedade, relações sociais, poder, trabalho e natureza (Ministério da Educação, 1998, p. 337).

Esses objetivos para o ensino de História mediaram a elaboração de obras didáticas e seleção de conteúdos para as séries iniciais a partir da ideia de que aprender História estaria relacionado com o entendimento do aluno de conceitos básicos para a apreensão do conhecimento histórico. Entre estes conceitos entendidos como fundamentais para o ensino de História, estariam os conceitos de tempo, espaço e sociedade.

Outro foco irradiador de seleção de conteúdos para as séries iniciais foram os $\mathrm{PCN}^{10}$ de História que delimitam assim o que deve ser ensinado.

Os conteúdos propostos estão constituídos, assim, a partir da história do cotidiano da criança (o seu tempo e o seu espaço), integrada a um contexto mais amplo, que inclui os contextos históricos. Os conteúdos foram escolhidos a partir do tempo presente no qual existem materialidades e mentalidades que denunciam a presença de outros tempos, outros modos de vida sobreviventes do passado, outros costumes e outras modalidades de organização social, que continuam de alguma forma, presentes na vida das pessoas e da coletividade. Os conteúdos foram escolhidos, ainda, a partir da idéia de que conhecer as muitas histórias, de outros tempos, relacionadas ao espaço em que vivem, e de outros espaços, possibilita aos alunos compreenderem a si mesmos e a vida coletiva de que fazem parte (PCN, 1997, p. 34).

A partir da década de 1990, do século XX, são estes dois documentos que acabam por delimitar aquilo que seriam os conteúdos a serem ensinados

\footnotetext{
${ }^{10}$ Parâmetros curriculares nacionais foram propostos pelo Ministério da Educação no ano de 1996. Constituem-se em diretrizes, que orientam a educação básica no Brasil, e são elaborados por disciplinas. Não sendo obrigatória sua utilização como referência.
} 
no ensino fundamental. Os PCN são construídos como parâmetros de ensino a serem observados nas elaborações de currículos nos estados e municípios brasileiros. O PNLD é um sistema de avaliação que ao indicar aquilo que entende como conteúdos para um livro didático, acaba também por influenciar a escolha de conteúdos nas séries iniciais e finais do ensino fundamental, pois ao avaliar os livros didáticos e posteriormente distribuílos para as escolas determina aquilo que será ensinado.

Nas séries iniciais do ensino fundamental a importância do livro didático na seleção de conteúdos de História a serem ensinados é muito grande. A formação generalista do professor deste nível de ensino faz com ele se apóie constantemente nos materiais didáticos em busca de sustentação para as práticas em sala de aula. A escolha dos conteúdos e os métodos de ensino acabam por ser definidos de forma geral pelo livro didático selecionado pela escola.

O livro didático como disseminador de conteúdos autorizados e legitimados pela ciência da história também tem que ser discutido como formador de identidades e fiel depositário de memórias e valores. Ao pensarmos a problemática da construção de identidades por meio dos conteúdos determinados pelos livros didáticos, precisamos estar atentos ao fato de que a maioria dos livros didáticos utilizados no ensino fundamental para as séries iniciais são livros denominados de livros regionais.

Os livros de história regionais cumprem diversas tarefas desde a anunciada por Chopin "como a função referencial, ligada à tradução dos conteúdos de ensino presentes nos programas e currículos (CHOPIN, 2004), até a questão central da seleção de conteúdos em História para as séries iniciais: a história local. De acordo com Circe Bitencourtt:

A história local tem sido indicada como necessária para o ensino por possibilitar a compreensão do entorno do aluno, identificando o passado sempre presente nos vários espaços de convivência escola, casa, comunidade, trabalho, lazer - e igualmente por situar os problemas significativos da história do presente (BITTENCOURT, 2004, p. 168). 
Nesse sentido, entendemos a importância que a história local ganha como conteúdo nas séries iniciais, nos aproximando do sentido atribuído por Vygotsky para a aprendizagem da História. Assim, o professor ao escolher como conteúdo as possibilidades de desenvolver na criança a capacidade de se articular com seu mundo permite que ela desenvolva as condições para a apreensão do conhecimento histórico.

O estudo da história local faz parte da cultura escolar brasileira desde o Império. Estudava-se a história das províncias e depois dos estados da Federação onde pertencia o aluno, esta história local ou regional integrou os programas escolares da escola elementar no Brasil com o objetivo de criar um sentimento de pertença e identidade com o território, a terra natal. Segundo Bittencourt (2004), este sentimento antecipou a constituição de uma identidade nacional que justificava e justifica plenamente a inserção das histórias dos Estados como conteúdo histórico escolar.

A manutenção atualmente das histórias locais e regionais nos currículos das séries iniciais está relacionada às teorias que indicam que o lugar mais próximo seria um dos campos de articulação entre a necessidade de estudo de contextos diversos e a vida do aluno. Este espaço de confluência daria oportunidade para o aluno de constituir a partir de referências conhecidas, uma reflexão sobre o outro, seja espacial ou temporal. Esta demanda de práticas educativas relacionadas ao entorno do aluno tem suportes também nas teorias psicológicas que sustentam o ensino nas séries iniciais, tais teorias que vem sendo utilizadas desde o século XIX argumentam que a criança nas séries iniciais estaria no estágio de desenvolvimento concreto ${ }^{11}$. Estas informações provocaram uma série de equívocos, entre elas a proposição do ensino de História por meio dos círculos concêntricos, este estudo baseado em áreas espaciais das mais próximas para áreas mais distantes, por exemplo: casa, escola, bairro, cidade, estado, país, mundo foi e ainda é preponderante em muitas escolas no Brasil.

\footnotetext{
${ }^{11}$ Esta teoria baseada no pensamento de Jean Piaget foi e ainda é muito forte entre os professores das séries iniciais que argumentam a dificuldade do ensino de História para crianças por conta da impossibilidade de tornar concreto o conhecimento histórico.
} 


\section{A escolha de conteúdos para o ensino de História nas séries iniciais na perspectiva da educação histórica}

A educação histórica ${ }^{12}$ propõe um estudo com a aprendizagem e ensino de História. Tem o objetivo de entender as relações que alunos e professores estabelecem com o conhecimento histórico, com os conceitos e as categorias históricas, assim como as ideias substantivas e ideias de segunda ordem da disciplina de História. A educação histórica tem especial interesse na forma pelo qual o trabalho com fontes, as estratégias de ensino, os materiais didáticos, os objetos históricos, entre outros, colaboram para a formação das ideias históricas e da consciência histórica de alunos e professores.

Para se compreender o processo de construção do conhecimento, a educação histórica divide os conceitos fundamentais em história em duas tipologias: Conceitos substantivos e conceitos de segunda ordem. Por conceitos substantivos entende-se os conteúdos da História, por exemplo o conceito de industrialização, renascimento, revolução. Enquanto conceitos de segunda ordem: são conceitos que estão envolvidos em qualquer que seja o conteúdo a ser aprendido. Entre os conceitos de segunda ordem, podemos citar continuidade, progresso, desenvolvimento, evolução, época enfim que se referem à natureza da História, como explicação, interpretação, compreensão (LEE, 2001).

Também são considerados conceitos de segunda ordem aqueles relacionados às formas e à compreensão do conhecimento histórico, como o conceito de narrativa, evidência, inferência imaginação e explicação histórica (SCHMIDT, 2009, p. 37). As ideias históricas dos alunos são trabalhadas com estes conceitos no momento que o professor deixa de lado, nas séries iniciais, apenas os exercícios mecânicos, como responder perguntas, explicar

\footnotetext{
${ }^{12}$ Segundo Isabel Barca, a educação histórica tem se constituído a partir de uma fundamentação teórica específica, sendo que as áreas contempladas são: a Epistemologia da História, a Metodologia de Investigação em Ciências Sociais, a Psicologia Cognitiva e a História. Os focos de investigação são: princípios, fontes, tipologias e estratégias de aprendizagem em História, com o pressuposto que a intervenção do professor na qualidade da aprendizagem requer um conhecimento prévio e sistemático das ideias históricas dos alunos (BARCA, 2005, p. 15).
} 
ou caracterizar situações ou apenas leitura dos conteúdos do livro. Esta forma de trabalhar em sala de aula desvincula os conceitos substantivos dos conceitos de segunda ordem, o que não pode acontecer.

O trabalho com o pensamento histórico exige que as ideias de segunda ordem sejam levadas em consideração no momento da aprendizagem, por exemplo a questão das hipóteses e da narrativa. É preciso solicitar aos alunos que levantem hipóteses sobre os conteúdos e elaborem narrativas faladas e escritas sobre as hipóteses levantadas. Nas séries iniciais, este tipo de conhecimento que leva em consideração as ideias de segunda ordem, ou seja, da natureza da história, é mais significativo que as ideias substantivas, pois se referem aos procedimentos necessários para se dialogar com os conhecimentos históricos, proporcionando desta forma sentido aos conceitos substantivos, por exemplo: Quando o professor em sua sala de aula apresenta a história do município para o aluno destacando os principais acontecimentos como data de fundação, primeiros moradores etc. podemos afirmar que ele está trabalhando apenas com os conteúdos substantivos, mas quando o professor provoca o conhecimento com os conceitos de segunda ordem, ele traz para o processo de ensinoaprendizagem a evidência, a imaginação, a narrativa.

Entendemos que o desenvolvimento do pensamento histórico precisa ser objeto do ensino de História desde os anos iniciais do ensino fundamental. É preciso desenvolver o pensar historicamente que pode ser evidenciado nas formas como os indivíduos entendem o conhecimento histórico. Não colocamos em oposição os conteúdos históricos baseados em eventos, datas e fatos e uma aprendizagem da história baseada no desenvolvimento do pensamento histórico. O que defendemos é uma estreita articulação na narrativa histórica que permita entender a relação que os sujeitos têm com os conceitos, ideias, conteúdos, cuja referência é a própria epistemologia da história (SCHMIDT; BRAGA, 2001, p. 64).

Acreditamos que a criança elabora suposições sobre a história utilizando aquilo que Hilary Cooper (2004) chama de imaginação histórica, a qual defendemos que deve ser aproveitada no processo de aprendizagem da história, ou seja, da história conhecimento e, consequentemente, do desenvolvimento do pensamento histórico (CAINELLI, 2006). 
Gago (2009) e Barca (2008) afirmam ser possível que as crianças aprendam uma história genuína com algum grau de elaboração, contanto que as tarefas, os tópicos e os contextos em que são apresentados tenham significado para elas e que o desenvolvimento do raciocínio histórico processe-se com oscilações, e não de uma forma simplista em determinadas situações e de uma forma mais elaborada em outras. Barca afirma que:

O saber histórico genuíno constrói-se, com base nos significados tácitos que cada sujeito atribui às mensagens, por inferência sobre múltiplas fontes, diversas no seu suporte e nos seus pontos de vista. O pensamento histórico não se limita a uma interpretação parcelar e linear das fontes; alimenta-se de narrativas progressivamente construídas, criticadas e reconstruídas. Este caminho é percorrido por quem interpreta e por quem_aprende, e é essencial para a construção de sínteses progressivamente contextualizadas (BARCA, 2004, p. 15).

Nesse sentido, a escolha de conteúdos em História precisa estar articulada com os objetivos para seu ensino e os objetos que definem seu estatuto epistemológico. Autores como LEE (2001, 2004, 2006), Barca (2001, 2009) e Schmidt e Braga $(2006,2007)$ argumentam sobre a existência de uma cognição histórica que seria a possibilidade de a criança ser capaz de desenvolver raciocínios de forma elaborada, no momento em que são criadas condições de aprendizagem significativas, em relação com as suas vivências prévias. Assim, o desenvolvimento do pensamento histórico se articularia com o modo de pensar de cada criança a partir daquilo que lhe é significativo, distinguindo as questões históricas a partir do momento em que faz inferências e diferencia a História disciplina das outras maneiras de representar o passado, sejam elas espontâneas ou não.

Barca argumenta que:

a perspectiva da educação histórica, aquilo que chamamos de saber histórico genuíno constrói-se, com base nos significados tácitos que cada sujeito atribui às mensagens, por inferência sobre múltiplas fontes, diversas no seu suporte e nos seus pontos de vista (BARCA, 2004, p. 121). 
Autilização do livro didático e a seleção deconteúdos já determinadas faz com que o professor priorize certas habilidades ou operações mentais de cunho mais didático do que relacionados ao pensamento histórico, o conteúdo é dado de forma fragmentada e a subjetividade da aprendizagem do pensamento fica perdida. É necessário que a escolha de conteúdos recaia sobre a ciência da história como categoria fundamental priorizando como método a importância da narrativa. A maneira como hoje o professor sugere o registro do conhecimento histórico acaba por provocar uma separação entre as formas de aprender a pensar e as formas de pensar com e a partir da história, ou seja, entre a aprendizagem e seu objeto (GRENDHEL, 2009).

Nesse sentido, para educação histórica, a essência do ensino seria a constituição de narrativas concebidas pela descrição, análise e explicação. Outro fator importante no desenvolvimento do pensamento histórico está relacionado ao levantamento de hipóteses e, principalmente, não ensinar história como repetição mecânica e sim como experiências únicas complexas que constituiriam a consciência histórica (GRENDHEL, 2009).

Nas palavras de Rusen, podemos entender o que significa ensinar história, tendo como objeto o conhecimento histórico a partir do significa para os indivíduos, do sentido que confere a vida cotidiana dos homens no tempo.

A História deve ser apreendida como uma experiência cultural que coloca objetivos orientativos a disposição do aluno. Tal diferenciação levaria a uma didática histórica organizada com os assuntos arrumados de acordo com um cânone histórico de objetos. A dinâmica da subjetividade fica estagnada quando a História é ensinada como algo certo, dado. O conhecimento histórico que é aprendido simplesmente pela recepção evita - ao invés de promover - a Habilidade de dar sentido a história, e se orientar de acordo com a experiência histórica. Um sentido que é simplesmente "dado" não pode ser observado como um sentido que é ignorado em sua função fundamental de organizar o conhecimento. Além disso, a subjetividade como fonte de novas questões e uma boa vontade para novas experiências acaba não sendo explorada. E também, o conhecimento histórico adquirido não pode ser empregado de forma produtiva para orientar os problemas da vida prática. Quando o conhecimento histórico se torna muito objetivo, 
ele perde sua função de orientação cultural - e no fim das contas, o conhecimento histórico é produzido exatamente para preencher esta função cultural (RUSEN, p. 96, 1993).

Esta citação de Rusen indica muito bem o sentido de ensinar História hoje e como esta nova forma de pensar a aprendizagem da História interfere na forma de escolha dos conteúdos a serem trabalhados em sala de aula. $\mathrm{O}$ autor é enfático quando afirma que ensinar História como algo pronto e acabado, com conteúdos pré-definidos, sem levar em conta o contexto e os sujeitos envolvidos no processo de ensino aprendizagem, pode levar a um ensino que não desenvolve o que é mais importante como função do ensinar História que é orientar os problemas da vida prática.

Este sentido do ensinar História não significaria não ter conteúdos para serem ensinados, mas olhar para estes conteúdos a partir da possibilidade de construir com os alunos novas questões diante de conteúdos/temas postos pela historiografia. Aprender História é discutir evidencias, levantar hipóteses, dialogar com os sujeitos, os tempos e espaços históricos. É olhar para o outro em tempos e espaços diversos. A experiência de cada um alarga-se com a compreensão das experiências dos outros (BARCA, 2009). Diante desta nova perspectiva para o ensino de História, a seleção de conteúdos e a definição do que seriam conteúdos em História precisa levar em conta a experiência histórica de nossos antepassados organizados no conhecimento historiográfico produzido pelos historiadores.

A mudança mais complexa é a relação do professor com o livro didático de História. Neste tipo de metodologia e de entendimento dos conteúdos históricos, o professor não poderia ter o livro como detentor dos saberes a serem ensinados. O livro serviria apenas de articulador dos conteúdos históricos que seriam trabalhados em sala de aula. No entanto, estes conteúdos teriam que ser definidos pelo professor. A seleção se daria pela organização do trabalho didático tendo como pressuposto as ideias históricas dos alunos e isto só seria possível tendo o professor o objetivo de orientar suas propostas e escolhas de conteúdos a partir do conhecimento com os alunos e não de uma relação mecanicista com o conhecimento histórico. 


\section{A narrativa histórica como possibilidade metodológica em aulas de História nas séries iniciais}

Ensinar História nas séries iniciais na perspectiva de proporcionar aos alunos se entenderem no tempo em que vivem a partir do entendimento dos sujeitos de outros tempos e lugares, pressupõe a possibilidade da compreensão desta história por meio da narrativa. A perspectiva que trabalhamos a narrativa neste momento é ancorada nas ideias de Husbands (2003). Este autor entende a narrativa escolar como uma das formas pelas quais alunos e professores dão sentido ao passado histórico, quando pensam sobre as versões do passado. Para ele, por meio das narrativas torna-se possível, em aulas de História, tratar de ideias mais abstratas sobre as suposições e crenças das sociedades do passado, sobre as formas como trabalharam ou fracassaram, e como as pessoas representavam suas relações com outros (GEVAERD, 2009, p. 142).

Para Husbands (2003) trabalhar com a narrativa escolar implicaria alguns procedimentos importantes no desenvolvimento das aulas de História. Para conseguir o objetivo de compreensão da História por meio da narrativa, o professor precisa não só, como afirma Gevaerd:

Contar histórias, mas também pedir aos alunos que as recontem; submetê-las a um exame crítico, criando um sentido da sua naturalidade, assim como da sua lógica. Envolver uma dúvida cética implícita sobre o caráter das histórias que contamos. Significa relacionar histórias áqueles princípios organizadores - as idéias de causa, continuidade, mudança - do complexo discurso histórico (GEVAERD, 2009, p. 143 apud HUSBAND, 2003, p. 51).

A aprendizagem da História desta forma leva em consideração e importância não os conteúdos dados como naturais para a história, mas sim as narrativas sobre os acontecimentos, vinculando o narrar à experiência do tempo de maneira que o passado possa tornar-se presente no quadro cultural da orientação para vida prática contemporânea (RUSEN, 2001, p. 55). A narrativa escolar, seja a do livro didático, a do professor ou a do aluno, precisa acima de tudo resolver problemas com a perspectiva de expressar ideias em torno do conhecimento histórico. 
A narrativa demonstra a relação entre consciência histórica, valores morais e argumentação (RUSEN, 1993, p. 64). A partir deste argumento, se entende a narrativa histórica como o recontar o que aconteceu, constituindo este recontar não uma simples descrição, mas também uma explicação. A narrativa histórica, entendida como explicativa, tenta responder a questões do como e porque existiram as situações do passado em estudo (GAGO, 2009, p. 180).

As investigações realizadas no âmbito do projeto de pesquisa em educação histórica priorizam as relações de ensino-aprendizagem no ambiente de sala de aula. No sentido de perceber como se dá a progressão do conhecimento histórico, investigamos como se elabora o pensamento histórico nas atividades cotidianas de sala aula de alunos do ensino fundamental.

Nesta tarefa, dialogamos neste ambiente com os conteúdos escolhidos e trabalhados pela professora nos momentos dedicados a aula de História de uma turma de terceira série (quarto ano) do ensino fundamental. As observações realizadas pelos pesquisadores têm como foco as narrativas que os alunos elaboram, sejam como exercício escrito, falado ou desenhado no caderno.

Neste artigo, nos deteremos na análise de narrativas dos alunos relacionadas a deslocamentos temporais apresentados em um instrumento de análise elaborado pelos pesquisadores do projeto $^{13}$. Entre as questões deste instrumento, selecionamos as questões: Como você acha que será um museu do futuro? Quais objetos estarão guardados neste museu?

Algumas respostas: "Eu acho que teria coisas desse tempo de hoje. Não sei." e "Acho que com coisas da época que estamos".

Podemos ver que a criança elabora relações entre o presente (hoje), o passado (ontem), o futuro (amanhã), mas não o faz de forma segura, mas no raciocínio que demonstra o entendimento de que os objetos que estarão no museu pertencem ao passado e que a formação do futuro está no passado.

Outras respostas: "Não sei prever o futuro" e "Não sei é o futuro".

\footnotetext{
${ }^{13}$ Participaram desta fase do projeto as professoras Marlene Cainelli e Magda Tuma e os estagiários Lidiane Lourençato, Diego Monteiro e Talyta Selari.
} 
Neste caso, a narrativa indica um tempo sem continuidade histórica, para as crianças presente e futuro não tem relação, assim como o futuro aparece como possibilidade não determinada, e ainda: "Será com mais tecnologia e bastante coisas do nosso tempo, estarão guardadas as coisas mais valiosas?" e "Será mais interessante que os de hoje e terá mais coisas para ver. Coisas que existem agora?"

Nestas respostas, podemos perceber além da relação de diálogo temporal que as crianças acreditam viverem em um tempo mais interessante que as pessoas do passado; demonstram também uma percepção de aceleração temporal e mudanças tecnológicas para o futuro.

Quando ensinamos sobre a História, trabalhamos com acontecimentos que são selecionados como conteúdos pela importância que representam nas sociedades, nesse sentido a História tenta compreender os atos humanos do passado. A História pode englobar uma época ou uma vida individual, o estudo de uma cidade ou de uma nação. "Estuda-se história para poder pensar o outro. Para entender a dialética da mudança e da permanência. Ver que a vida não é retilínea. E que o futuro pode ser diferente do presente. Mais do que entender o passado, estudar a história é trabalhar a diferença, a tolerância." (NADAI, 1991, p. 16). Nesse sentido, a escolha dos conteúdos e a forma como ensinamos História precisa refletir esta forma de pensar a função do ensino de história, ou seja, trabalhar a diferença e a tolerância na formação de cidadãos conscientes da sua história e da história do outro.

\section{Referências}

BARCA, I. Concepções de adolescentes sobre múltiplas explicações em História. In. _ _ (Org.). Perspectivas em Educação Histórica. Actas das Primeiras Jornadas Internacionais de Educação Histórica. Universidade do Minho, p. 29-44, 2001.

. Investigação em Educação Histórica: fundamentos, percursos e perspectivas. In. OLIVEIRA, M.; CAINELLI, M.; OLIVEIRA, A. (Org.). Ensino de História: múltiplos ensinos em múltiplos espaços. Natal: EdUFRN, 2008, p. 23-33. 
BEZERRA, H. G. Conceitos básicos: Ensino de História: conteúdos e conceitos básicos. In: KARNAL, L. (Org.). História na sala de aula: práticas e propostas. São Paulo: Contexto, 2003, p. 37-49.

BITTENCOURT, C. M. F. Ensino de História: fundamentos e métodos. São Paulo: Cortez, 2004.

BORNE, D. Comunidade de Memória e rigor crítico. In: BOUTIER, J.; JULIA, D. (Org.). Passados Recompostos: campos e canteiros da história. Rio de Janeiro: UFRJ; FGV, 1998, p. 133 a 144.

CAINELLI, M.; OLIVEIRA, S. Entre o conhecimento histórico e o saber escolar: uma reflexão sobre o livro didático de História para as séries iniciais. In: OLIVEIRA, M. Dias; STAMATTO, M. I. S. (Org.). O livro didático de História: políticas educacionais, pesquisas e ensino. Natal: EDUFRN, 2007, p. 89- 98.

COOPER, H. O pensamento histórico das crianças. In: BARCA, I. (Org.). Para uma Educação Histórica de Qualidade. Actas das IV Jornadas Internacionais de Educação Histórica. Universidade do Minho, p. 55-76, 2004.

CHOPPIN, A. História dos livros e das edições didáticas: sobre o estado da arte. Educação e Pesquisa, São Paulo, v.30, n.3, p. 549-566, set./dez. 2004. GAGO, M. Uso(s) e "utilidades" da narrativa histórica na aula: um olhar de professores acerca da aprendizagem dos estudantes. In: BARCA, Isabel; SCHMIDT, M. A. (Org.). Aprender História: perspectivas da educação Histórica. Ijuí: Unijuí, 2009, p. 175-196.

GONÇALVES, M. de A. História local: o reconhecimento da identidade pelo caminho da insignificância. In: MONTEIRO, Ana Maria et al. (Org.). Ensino de História: sujeitos, saberes e práticas. Rio de Janeiro: Mauad X; Faperj, 2007, p. 175- 186.

GRENDHEL, M. T. De como a didatização separa a aprendizagem histórica do seu objeto: um estudo a partir da analise de cadernos escolares. 2009. Tese de Doutorado em Educação. Universidade Federal do Paraná, Curitiba, 2009.

HOBSBAWN, Eric. Sobre a História. Companhia das Letras, 1998. 
LEE, P. Progressão da compreensão dos alunos em História. In: BARCA, I. (Org.). Perspectivas em Educação Histórica. Actas das Primeiras Jornadas Internacionais de Educação Histórica. Universidade do Minho, p. 13-29, 2001.

NADAI, E.; LAGOA, A. História: O bonde que a escola perdeu. Revista Nova Escola. São Paulo: Abril, n. 53, p. 16, Nov.1991.

OLIVEIRA, S. R. F. de. O ensino de História nas séries iniciais: cruzando as fronteiras entre a História e a Pedagogia. História \& Ensino: Revista do Laboratório de Ensino de História. Londrina, v. 9, p. 259-272, 2003.

RUSEN, J. Razão Histórica: teoria da história:fundamentos da ciência Histórica. Editora Universidade de Brasília, 2001.

. Studies in metahistory. Tradução de Marcio E. Gonçalves. Pretoria: Human Sciences Research Council, 1993.

SCHMIDT, M. A. O ensino de História e os desafios da formação da consciência histórica. In. MONTEIRO, Ana Maria. et. al. (Org.). Ensino de História: sujeitos, saberes e práticas. Rio de Janeiro: Mauad X: Faperj, 2007, p. 187-198.

. Cognição histórica situada: que aprendizagem histórica é esta? In: BARCA, I.; SCHMIDT, M. A. (Org.). Aprender História: perspectivas da educação Histórica. Ijuí: Editora Unijuíi, 2009, p. 21 - 51.

Data de registro: $18 / 03 / 2010$

Data de aceite: 16/02/2011 